\title{
Marfan syndrome: clinical diagnosis and management
}

Marfan syndrome is a multisystem connective tissue disorder usually associated with mutation in fibrillin, and occasionally with mutation in TGFBR1 or 2. The clinical diagnosis is made using the Ghent nosology, which will unequivocally diagnose or exclude Marfan syndrome in $86 \%$ of cases. Use of a care pathway can help implementation of the nosology in the clinic. The penetrance of some features is age dependent, so the nosology must be used with caution in children. Molecular testing may be helpful in this context. The nosology cannot be used in families with isolated aortic dissection, or with related conditions such as Loeys-Dietz syndrome, although it may help identify families for further diagnostic evaluation because they do not fulfill the nosology, despite a history of aneurysm. Prophylactic medical (eg $\beta$-blockade) and surgical intervention is important in reducing the cardiovascular complications of Marfan syndrome. Musculoskeletal symptoms are common, although the pathophysiology is less clear - for example, the correlation between dural ectasia and back pain is uncertain. Symptoms in other systems require specialist review such as ophthalmology assessment of refractive errors and ectopia lentis. Pregnancy is a time of increased cardiovascular risk for women with Marfan syndrome, particularly if the aortic root exceeds $4 \mathrm{~cm}$ at the start of pregnancy. High-intensity static exercise should be discouraged although low-moderate intensity dynamic exercise may be beneficial. The diagnosis and management of Marfan syndrome requires a multidisciplinary team approach, in view of its multisystem effects and phenotypic variability.

In brief

- Variable autosomal dominant disorder, characteristically with cardiovascular, eye and skeletal, features.

- The minimal birth incidence is 1 in 9800

- $27 \%$ of cases arise from new mutation

- Mutation in fibrillin-1 on chromosome 15 is detected in $66-91 \%$ of cases

- Some cases may be due to mutation in TGF $\beta$ Rl or TGF $\beta$ R2
- TGF $\beta$ R1 or TGF $\beta$ R2 are also associated with Loeys-Dietz syndrome, and TGF $\beta$ R2 with familial thoracic aortic aneurysm

- The clinical diagnosis in adults should be made using the Ghent criteria

- The Ghent criteria are unreliable in children

- Prophylactic medical treatment to protect the aorta with regular follow-up helps prevent or delay serious complications

- Prophylactic aortic surgery should be considered when the aortic root at the Sinus of Valsalva exceeds $5 \mathrm{~cm}$
John CS Dean ${ }^{*, 1}$

Department of Medical Genetics, NHS Grampian, Argyll House, Foresterhill, Aberdeen, AB25 2ZR, UK

European Journal of Human Genetics (2007) 15, 724-733; doi:10.1038/sj.ejhg.5201851; published online 9 May 2007

Keywords: Marfan; diagnosis; management

*Correspondence: Dr John CS Dean, Department of Medical Genetics, Argyll House, Foresterhill, Aberdeen AB25 2ZR, Scotland, UK.

Tel: + 44 (0) 1224 552120; Fax: + 44 (0) 1224 559390;

E-mail: j.dean@abdn.ac.uk

Received 10 January 2006; revised 22 March 2007; accepted 4 April 2007; published online 9 May 2007

\section{Introduction}

Marfan syndrome (MIM 154700) is a variable, autosomaldominant disorder of connective tissue whose cardinal features affect the cardiovascular system, eyes and skeleton (Figure 1). The minimal birth incidence is around 1 in 9800. ${ }^{1}$ Progressive aortic dilatation, usually maximal at the sinus of Valsalva, associated with aortic valve incompetence leads to aortic dissection or rupture and is the principal cause of mortality, but mitral valve prolapse with incompetence may be significant, and lens dislocation, myopia and arthritis associated with chronic joint laxity can cause substantial morbidity. The diagnosis is 


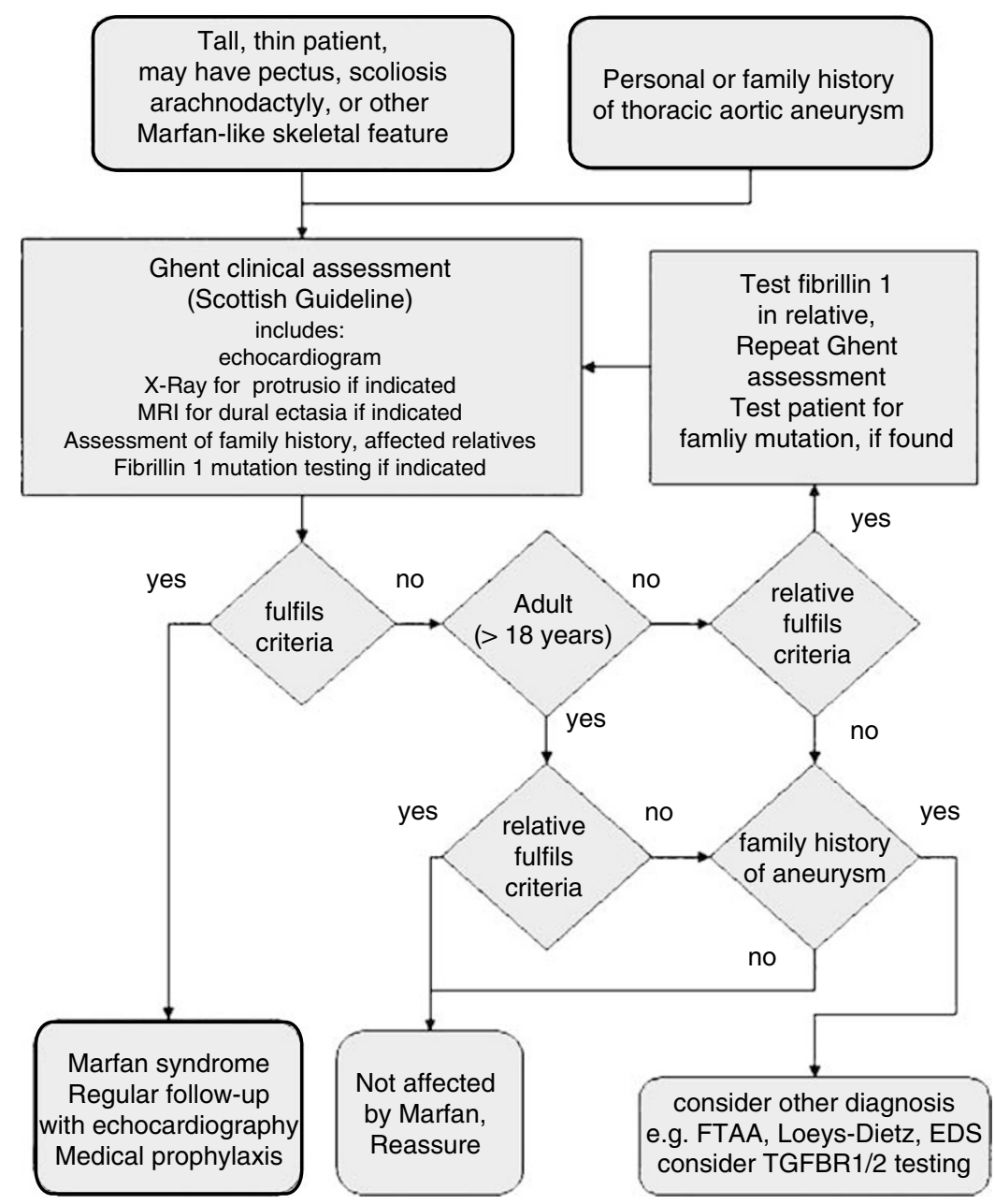

Figure 1 Algorithm for using the Ghent nosology in the diagnosis of Marfan syndrome and related disorders. Relative in this diagram means first degree relative. Consider TGFBR1 and 2 testing in Marfan syndrome if no ocular features.

commonly considered in a young person with a tall, thin body habitus, long limbs, arachnodactyly, pectus deformities and sometimes scoliosis (Figures 2 and 3). Other findings in the clinic such as a high arched palate with dental crowding, skin striae distensae, recurrent hernia or recurrent pneumothorax may increase suspicion. Family history may be helpful, but around $27 \%$ of cases arise from new mutation. ${ }^{1}$ In 1991, fibrillin-1 gene mutation on chromosome 15 was identified as a cause of Marfan syndrome, ${ }^{2}$ but molecular testing is not as diagnostically useful as was originally hoped. Fibrillin-1 mutation causes some Marfan-like disorders with a better prognosis (eg MASS phenotype, MIM 604308, mitral valve prolapse, mild non-progressive aortic dilatation, skin and skeletal features, or isolated ectopia lentis, MIM 129600), ${ }^{3}$ and between 9 and 34\% of bona fide Marfan patients have no identifiable fibrillin-1 mutations using current testing techniques. ${ }^{4,5}$ Recently, mutations in the transforming growth factor $\beta$-receptor 2 (TGFBR2) gene on chromosome 3 and in the TGFBR1 gene on chromosome 9 were found in some families with apparent Marfan syndrome. ${ }^{6-8}$ These 'Marfan syndrome type 2 ' (MIM 154705) ${ }^{9}$ families seem less likely to have ectopia lentis. TGFBR2 mutations at the R460 codon have also been described in families with the chromosome 3-linked form of familial thoracic ascending aortic aneurysm ${ }^{10,11}$ (FTAA3, MIM 608967), and TGFBR1 and 2 mutations are found in Loeys-Dietz syndromes type 1 and $2 .{ }^{12,13}$

To make the diagnosis of Marfan syndrome more consistent and of more prognostic value, the Berlin diagnostic criteria of 1988 were revised and the clinical features codified as the Ghent nosology in $1996 .{ }^{14}$ Using this, nosology should help identify which patients with a Marfan-like build are at risk of cardiovascular complications, needing regular follow-up with prophylactic medical and surgical treatment, and which can be reassured that 


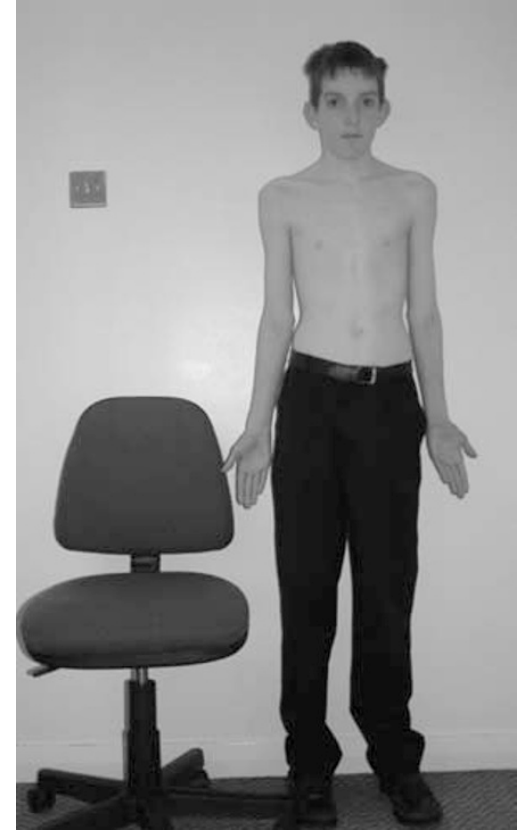

Figure 2 Boy aged 12 years 3 months with tall stature, joint hypermobility, a high arched palate with dental crowding, arachnodactyly and pes plenus. As he has no other clinical signs (particularly no eye signs), the diagnosis using the Ghent criteria can only be assured following echocardiography (showing a dilated aortic root), and with knowledge of his positive family history.
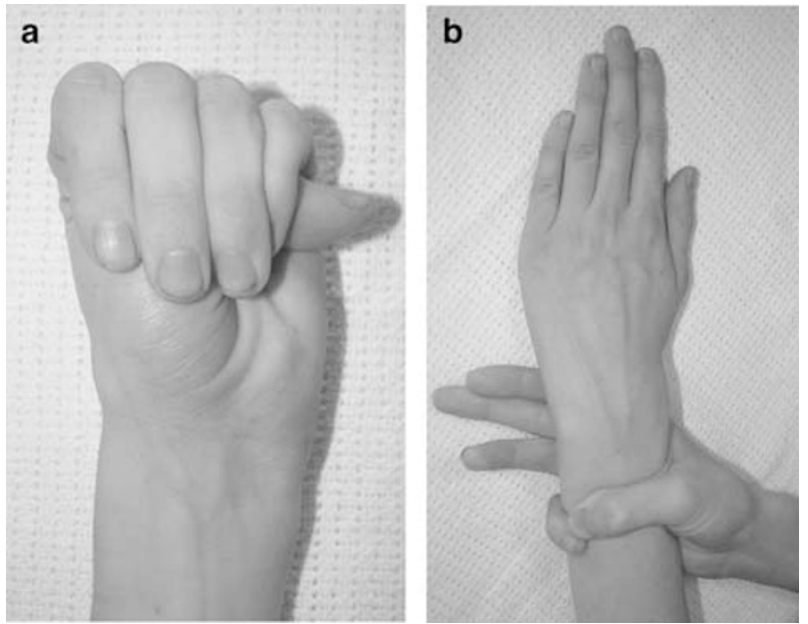

Figure 3 Arachnodactyly (a) positive thumb sign: entire thumbnail protrudes beyond ulnar border of hand. (b) Positive wrist sign: thumb and fifth finger overlap when encircling the wrist.

they are unaffected, avoiding the financial stigmatisation and lifestyle restrictions that may accompany the diagnosis. To further this aim, an integrated care pathway for clinical diagnosis and Scottish clinical guideline for management of Marfan patients was devised by a consensus group in $1999^{15}$ using SIGN methodology. ${ }^{16}$

\section{Implementing the Ghent nosology using the Scottish pathway}

In the Ghent nosology, clinical features are assessed within seven body 'systems', to determine whether that system provides a major criterion, or only system involvement (Table 1). A diagnosis of Marfan syndrome requires a major criterion in two systems and involvement of a third. The cardiovascular, ocular and skeletal systems can provide major criteria, or system involvement, the pulmonary system and skin/integument can provide only system involvement, the dura and family/genetic history provide only major criteria. The cardiovascular assessment requires measurement of the aortic diameter at the Sinuses of Valsalva, usually by transthoracic echocardiography (Figure 4), and comparison with normal values based on age and body surface area, calculated from height and weight. $^{14,17}$ Other imaging techniques such as transoesophageal echocardiography or MRI scanning may be helpful in some cases. Assessment of the skeletal system should include pelvic X-ray to detect protrusion acetabulae, $^{18}$ if a positive finding would provide system involvement, or change skeletal system involvement to a major criterion, such that a positive Marfan diagnosis could then be made in conjunction with other system findings. Similarly, lumbar MRI scan for dural ectasia, or genetic testing by linkage or mutation screening should be undertaken where a positive finding would make the diagnosis of Marfan syndrome. Ocular evaluation for myopia and lens subluxation requires ophthalmology assessment. The original nosology suggests measurement of axial globe length by ultrasound and keratometry, but these are not required in the Scottish pathway. ${ }^{15}$ Diagnosis in an index case and in a relative were originally described separately, as family/genetic history was assumed not to apply to an index case. The Scottish pathway allows the detection of a mutation known to cause Marfan syndrome (discovered in another family or known to affect fibrillin-1 function) to count as a major criterion in an index case, so that the same criteria may be applied to both index cases and relatives, as is implicit in the original nosology.

Because many Marfan features (echocardiographic findings, ${ }^{19}$ ectopia lentis, scoliosis, upper-lower segment ratio, protrusio acetabulae) are age dependent in their occurrence, ${ }^{20,21}$ younger patients with a family history of Marfan syndrome who do not fulfill the diagnostic criteria and younger Marfan-like patients with no family history who fail to meet the diagnostic criteria by one system should be offered repeat evaluations periodically (eg at least at ages 5, 10 and 15 years) until age 18 .

The differential diagnosis of a tall, young person with Marfan-like skeletal features includes homocystinuria (MIM 236300), Beals syndrome (MIM 121050), MarshallStickler syndrome (MIM 108300, 604841, 184840), EhlersDanlos syndrome (MIM 130050) and MASS phenotype (MIM 604308). Where there is a family history of aortic 
Table 1 Ghent diagnostic nosology

\begin{tabular}{|c|c|c|}
\hline System & Major criterion & Involvement \\
\hline Skeletal & $\begin{array}{l}\text { At least } 4 \text { of the following features: } \\
\text { - Pectus carinatum } \\
\text { - } \text { Pectus excavatum requiring surgery } \\
\text { - ULSR }<0.86 \text { or span:height }>1.05 \\
\text { - Scoliosis }>20^{\circ} \text { or spondylolisthesis } \\
\text { - Reduced elbow extension }\left(<170^{\circ}\right) \\
\text { - Pes plenus } \\
\text { - Protrusio acetabulae }\end{array}$ & $\begin{array}{l}2 \text { of the major features, or } 1 \text { major feature and } 2 \text { of } \\
\text { the following: } \\
\text { Pectus excavatum } \\
\text { - Hint hypermobility } \\
\text { - Crowding } \\
\text { - Characteristic face }\end{array}$ \\
\hline Ocular & Lens dislocation (ectopia lentis) & $\begin{array}{l}\text { Flat cornea } \\
\text { Increased axial length of globe (causing myopia) } \\
\text { Hypoplastic iris or ciliary muscle (causing decreased } \\
\text { miosis) }\end{array}$ \\
\hline Cardiovascular & $\begin{array}{l}\text { Dilatation of the aortic root } \\
\text { Dissection of the ascending aorta }\end{array}$ & $\begin{array}{l}\text { Mitral valve prolapse } \\
\text { Dilatation of the pulmonary artery, below age } 40 \\
\text { Calcified mitral annulus, below age } 40 \\
\text { Other dilatation or dissection of the aorta }\end{array}$ \\
\hline Pulmonary & None & $\begin{array}{l}\text { Spontaneous pneumothorax } \\
\text { Apical blebs }\end{array}$ \\
\hline Skin/Integument & None & $\begin{array}{l}\text { Striae atrophicae } \\
\text { Recurrent or incisional hernia }\end{array}$ \\
\hline $\begin{array}{l}\text { Dura } \\
\text { Genetic findings }\end{array}$ & $\begin{array}{l}\text { Lumbosacral dural ectasia } \\
\text { Parent, child or sibling meets these criteria independently } \\
\text { Fibrillin } 1 \text { mutation known to cause Marfan syndrome } \\
\text { Inheritance of DNA marker haplotype linked to Marfan } \\
\text { syndrome in the family }\end{array}$ & $\begin{array}{l}\text { None } \\
\text { None }\end{array}$ \\
\hline
\end{tabular}

Abbreviations: ULSR, Upper:lower segment ratio.

Having one of the features listed constitutes a major criterion or system involvement for all systems except the skeletal system, where more than one feature is needed.

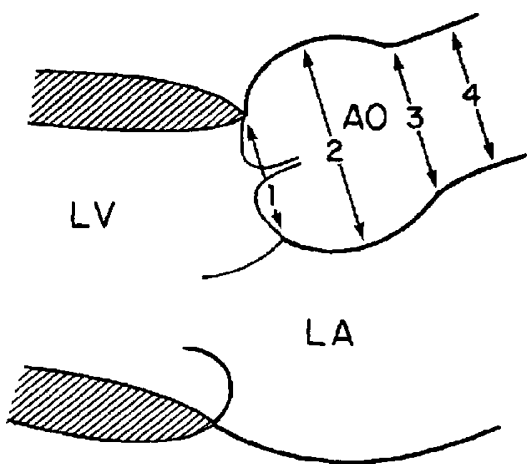

Figure 4 Diagram of the aortic root as seen at echocardiography. The aortic diameter should be measured at the aortic annulus (1), the sinuses of Valsalva (2), the supra-aortic ridge (3), and the proximal ascending aorta (4). In Marfan syndrome, dilatation usually starts at the sinuses of Valsalva, so this measurement is critical in monitoring the early evolution of the condition. Diameters must be related to normal values for age and body surface area. LV, left ventricle; LA, left atrium; Ao, aorta. After Roman et al. ${ }^{17}$

aneurysm, familial thoracic aortic aneurysm (FTAA) should be considered (MIM 607086, other features of Marfan syndrome may or may not be present). Additional clinical findings may suggest other disorders - bicuspid aortic valve and FTAA type 1 (MIM 607086), craniosynostosis, intellectual impairment and Shprintzen-Goldberg syndrome
(MIM 182212), arterial tortuosity or widespread aneurysms, hypertelorism, bifid uvula/cleft palate, craniosynostosis and Loeys-Dietz syndrome type $1^{12}$ (MIM 609192), arterial tortuosity or widespread aneurysms, visceral rupture, joint hypermobility, thin skin, and Loeys-Dietz syndrome type $2^{13}$ or intellectual impairment, velopharyngeal insufficiency and Lujan-Fryns syndrome (MIM 309520). The initial evaluation of patients with possible Marfan syndrome requires a multi-disciplinary approach including clinical genetics, cardiology, ophthalmology and radiology.

\section{Evaluating the use of the Ghent criteria}

Assessment of a patient using the Ghent nosology requires evaluation of 30 clinical features. Interpreting the outcome can be complex, yet this nosology is the 'gold standard' for clinical diagnosis. The Scottish care pathway and clinical guideline were devised to make use of the nosology more practical in the clinic. Between 1999 and 2006, 232 individuals were evaluated for possible Marfan syndrome in Aberdeen using the integrated care pathway. They comprised 95 probands and 137 at risk relatives (Table 2). In $20 \%$, Marfan syndrome could be unequivocally diagnosed using the Ghent criteria (24\% of probands, $18 \%$ of 
relatives), and in $66 \%$ (63\% of probands, $67 \%$ of relatives) it could be unequivocally excluded. Ten patients from five families had FTAA, on the basis of a personal or family history or aortic root dilatation or dissection in the absence of other Marfan syndrome features. Five families had isolated ectopia lentis. One case of neonatal Marfan syndrome did not fulfill the criteria, although she had recurrent pneumothorax, aortic root dilatation and joint laxity. Fourteen patients from one family did not fulfill the Ghent criteria, but were thought to have Marfan syndrome, as they had a connective tissue disorder causing various features of Marfan syndrome in different individuals, including aortic dilatation and dissection, ectopia lentis and skeletal findings, segregating with fibrillin-1linked DNA markers in the family. A definitely pathogenic fibrillin-1 mutation has not yet been detected, and no single individual fulfills the criteria independently. The three relatives whose Ghent assessment was 'uncertain' were all children, and will be re-assessed at follow-up. In children whose family diagnosis is Marfan syndrome (excluding the neonatal case), 7 were unequivocally affected, 17 were unequivocally unaffected and 3 were uncertain. Thus, the Ghent criteria did not establish Marfan status in $11 \%$ of children with a family history of Marfan syndrome, in keeping with the age-dependent penetrance of many Marfan features. This audit showed that the Ghent criteria were useful in diagnosing or excluding Marfan syndrome in $87 \%$ of probands and $85 \%$ of relatives. An equivocal outcome of the Ghent assessment in a proband should prompt consideration of an alternative diagnosis and further individual and family investigation. Confirming reported family history is vital, as the criteria will be misleading in families where other conditions have predisposed to arterial rupture (eg LoeysDietz syndrome, FTAA). Children must be kept under review, as the criteria will not reliably exclude Marfan syndrome in those under 18 (Table 3 ). Although the criteria are very useful in classical Marfan syndrome, the rapidly emerging information about disease phenotypes associated with fibrillin-1, TGFBR2 and TGFBR1 mutations may require some revision to include disorders such as LoeysDietz syndrome and FTAA. This would allow their more general use to guide molecular investigation of families and identify individuals at risk of aneurismal disease.

\section{Molecular pathology of Marfan syndrome and related disorders}

Classical Marfan syndrome is associated with mutation in fibrillin-1, an important component of the elastic microfibril. Fibrillin-1 is a $350 \mathrm{kD}$ glycoprotein, synthesized as a $375 \mathrm{kD}$ precursor that is processed and secreted into the extracellular matrix (ECM). It polymerises to form microfibrils and helps to stabilise latent transforming growth factor $\beta$-binding proteins (LTBPs) in the ECM. LTBPs hold transforming growth factor- $\beta$ (TGF $\beta)$ in an inactive state. ${ }^{9}$

Table 2 Application of Ghent criteria to Aberdeen Marfan clinic

\begin{tabular}{|c|c|c|c|c|c|c|c|}
\hline Ghent outcome & Diagnosis & Probands & $\%$ & Relatives & $\%$ & Total & $\%$ \\
\hline Ghent positive & Marfan & 23 & 24 & 24 & 18 & 47 & 20 \\
\hline Ghent negative & FTAA & 5 & 5 & 5 & 4 & 10 & 4 \\
\hline Ghent negative & $\mathrm{EL}$ & 5 & 5 & 0 & 0 & 5 & 2 \\
\hline Ghent negative & Neonatal Marfan & 1 & 1.5 & 0 & 0 & 1 & 1 \\
\hline Ghent negative & Marfan & 1 & 1.5 & 13 & 9 & 14 & 6 \\
\hline Ghent negative & Uncertain & 0 & 0 & 3 & 2 & 3 & 1 \\
\hline Ghent negative & Not affected & 60 & 63 & 92 & 67 & 152 & 66 \\
\hline Total & & 95 & 100 & 137 & 100 & 232 & 100 \\
\hline
\end{tabular}

Abbreviations: EL: isolated ectopia lentis; FTAA, familial thoracic aortic aneurysm.

Table 3 Key issues in the assessment of Marfan syndrome

- Diagnosis or exclusion of Marfan syndrome in an individual should be based on the Ghent diagnostic nosology.

- The initial assessment should include a personal history, detailed family history and clinical examination including ophthalmology examination and transthoracic echocardiogram.

- The aortic diameter at the Sinus of Valsalva should be related to normal values based on age and body surface area.

- The development of scoliosis and protrusio acetabulae is age dependent, commonly occurring following periods of rapid growth. $X$-ray for these features, depending on age, if a positive finding would make the diagnosis of Marfan syndrome.

- A pelvic MRI scan to detect dural ectasia is indicated if a positive finding would make the diagnosis of Marfan syndrome.

- The Ghent nosology cannot exclude Marfan syndrome in children, because of the age-dependent penetrance of many features.

- Younger patients with a positive family history but unsuccessful DNA testing and insufficient clinical features to fulfill the diagnostic criteria, and younger patients with no family history who miss fulfilling the diagnostic criteria by one system only should be offered further clinical evaluations at least until age 18, or until a diagnosis can be made.

- Family history of aortic aneurysm may represent a disorder such as familial thoracic aortic aneurysm, where the use of the Ghent nosology to assess risk in relatives is inappropriate. 
A failure of the interaction between fibrillin-1 and LTBPs may result in excess TGF $\beta$ signalling. ${ }^{22}$ Most fibrillin-1 mutations are missense, suggesting a dominant-negative effect on microfibrillar assembly. Ectopia lentis tends to be associated with missense mutations causing cysteine substitutions within the epidermal growth factor - like domains of the protein, but nonsense and frameshift mutations are seen in other cases, suggesting that while cysteine residues are important to the function of the suspensory ligament of the eye, either abnormal fibrillin or reduced amounts of fibrillin (haploinsufficiency) may cause other aspects of the Marfan phenotype. Marked variability in severity has been documented - different mutations in the same codon can cause either severe neonatal Marfan syndrome, or classical adult Marfan syndrome. Similarly, mutations in the central region of the gene (exons 24-32), sometimes called the 'neonatal region', may be associated with phenotypes ranging from severe neonatal Marfan syndrome to isolated ectopia lentis. $^{3,4,9}$ Although it was thought that abnormalities of microfibril structure might play an architectural role in causing the Marfan phenotype, it is now clear that the role of fibrillin- 1 in regulation of TGF $\beta$ signalling may be more pertinent. The discovery of TGFBR1 and TGFBR2 mutations in some cases supports this, as does evidence from mouse models. ${ }^{9,23}$ TGFBR1 or 2 mutation in humans are also associated with loss of elastin fibres and fibre disarray. Although the TGFBR1 and 2 mutations described so far are loss of function mutations, increased TGF $\beta$ signalling was found in patient tissues and Marfan mouse models, and TGF $\beta$ blockade by neutralising antibodies or angiotensin II type 1 (AT1) receptor blockers rescues the model phenotypes. ${ }^{9,12,24}$ The pathogenetic process must involve a complex disruption of TGF $\beta$ signalling yet to be elucidated.

\section{Aspects of clinical management in Marfan syndrome}

Although clinical management of many genetic disorders is not backed by extensive trials and case series, ${ }^{15}$ there are a large number of published studies of Marfan syndrome. Some of these studies will now be reviewed, based on work carried out by the Scottish Marfan Guideline Group, to provide a flavour of the evidence and dilemmas that influence Marfan management today.

\section{Cardiovascular system in Marfan syndrome}

Cardiovascular complications of Marfan syndrome include mitral valve prolapse and regurgitation, left ventricular dilatation and cardiac failure, pulmonary artery dilatation, but aortic root dilatation is the most common cause of morbidity and mortality (Table 4). Aortic valve incompetence usually arises in the context of a dilated aortic root, and the risk of aortic dissection increases when the diameter at the sinus of Valsalva exceeds $5 \mathrm{~cm},{ }^{17,25}$ when the aortic dilatation is more extensive, when the rate of dilatation exceeds $1.5 \mathrm{~mm}$ per year, and where there is a family history of aortic dissection. ${ }^{19,25-27}$ Myocardial infarction may occur if an aortic root dissection occludes the coronary ostia. Marfan syndrome mortality from aortic complications has decreased (70\% in 1972, 48\% in 1995) and life expectancy has increased (mean age at death $32 \pm 16$ years in 1972 versus $45 \pm 17$ years in 1998) ${ }^{1}$ associated with increased medical and surgical intervention.

The Marfan aorta is characterised by elastic fibre fragmentation and disarray, paucity of smooth muscle cells, and deposition of collagen and mucopolysaccharide between the cells of the media. These appearances are sometimes described as 'cystic medial degeneration' although there are no true cysts present. Mucopolysaccharide deposition in the valves may cause valve leaflet thickening. Elastic fibre degeneration in the aorta is associated with reduced distensibility in response to the pulse pressure wave. This abnormal aortic compliance can be detected at any age by echocardiography ${ }^{28}$ or gated MRI scanning, ${ }^{29}$ although it is less marked in children. Reduction of the systolic ejection impulse by $\beta$-blockers might be expected to reduce the risk of aortic dissection in Marfan syndrome. ${ }^{19}$ Studies in turkeys prone to aortic dissection showed improved survival with propranolol and two trials in Marfan patients (a randomised trial of propranolol therapy and a retrospective historically controlled trial of propranolol or atenolol therapy) demonstrated a reduced rate of aortic dilatation and fewer aortic complications in

Table 4 Key issues in cardiovascular management

- $\beta$-Blocker therapy should be considered at any age if the aorta is dilated, but prophylactic treatment may be more effective in those with an aortic diameter of less than $4 \mathrm{~cm}$.

- Risk factors for aortic dissection include aortic diameter greater than $5 \mathrm{~cm}$, aortic dilatation extending beyond the sinus of Valsalva, rapid rate of dilatation ( $>5 \%$ per year, or $1.5 \mathrm{~mm} /$ year in adults), and family history of aortic dissection.

- At least annual evaluation should be offered, comprising clinical history, examination and echocardiography. In children, serial echocardiography at 6-12 month intervals is recommended, the frequency depending on the aortic diameter (in relation to body surface area) and the rate of increase.

- Prophylactic aortic root surgery should be considered when the aortic diameter at the Sinus of Valsalva exceeds $5 \mathrm{~cm}$.

- In pregnancy, there is an increased risk of aortic dissection if the aortic diameter exceeds $4 \mathrm{~cm}$. Frequent cardiovascular monitoring throughout pregnancy and into the puerperium is advised. 
the treatment group. ${ }^{19,30}$ Some patients respond better than others, responders tending to be younger and showing improved aortic distensibility, reduced pulse wave velocity, smaller pre-treatment aortic diameters (less than $4 \mathrm{~cm}$ in one study). ${ }^{19,26,28,30-32}$ Poor response may be associated with more extensive elastic fibre degeneration, either due to a more severe mutation or more advanced disease. $\beta$-Blockade should therefore be considered in all Marfan patients, including children. Some patients may not tolerate $\beta$-blockers, and alternative drugs which reduce the ejection impulse such as calcium antagonists, $^{33}$ and angiotensin converting enzyme (ACE) inhibitors have been considered. ACE inhibitors also reduce vascular smooth muscle cell apoptosis in vitro through an angiotensin II type 2 (AT2) receptor-dependent mechanism (apoptosis is implicated in the cystic medial degeneration seen in the Marfan aorta ${ }^{34}$ ). This theoretical benefit may be in addition to any haemodynamic effects. Enalapril improved aortic distensibility and reduced the rate of aortic dilatation compared with $\beta$-blockers in one small clinical trial in children and adolescents. ${ }^{35}$ In a mouse model, the AT1 receptor antagonist losartan reduced aortic growth rate, and prevented elastic fibre degeneration, presumably through effects on TGF $\beta$ signalling as well as haemodynamic effects, although angiotensin II also stimulates Smad-2-dependent signalling in vascular smooth muscle cells and vessel wall fibrosis by an AT1 receptor-dependent but TGF $\beta$-independent mechanism. ${ }^{24}$ As ACE inhibitors reduce angiotensin II production, they will act on both AT1- and AT2-dependent pathways - the benefit or otherwise of inhibiting both pathways is unknown. In another study, abnormal flow-mediated vasodilation of the brachial artery was demonstrated in Marfan patients, although agonistmediated vasodilation was normal. ${ }^{36}$ This was attributed to abnormal endothelial cell mechanotransduction associated with abnormal fibrillin. There may therefore be other molecular targets for future pharmacological intervention.

If medical treatment fails, and the aortic root dilates to $5 \mathrm{~cm}$ or more, then prophylactic surgery should be considered. ${ }^{14,25,37}$ One study suggests the threshold diameter should be $0.5 \mathrm{~cm}$ lower in affected women. ${ }^{27}$ Other factors such as the rate of aortic growth, and family history of dissection should be taken into account. Numerous studies have shown better survival rates for prophylactic compared with emergency aortic surgery, ${ }^{25,38}$ and improved longevity for Marfan patients who undergo prophylactic surgery compared with their untreated relatives. $^{39}$ Alternative procedures include the Bentall composite graft repair, in which both the aortic root and the aortic valve are replaced, or a valve conserving technique such as re-implantation of the native aortic valve in a Dacron tube (described by David) or remodelling of the aortic root (described by Yacoub). ${ }^{40,41}$ The Bentall procedure has a low mortality in experienced hands with long-term survival of around $80 \%$ at 5 years and $60 \%$ at 10 years, ${ }^{42}$ but requires lifelong anti-coagulation post-operatively, whereas valve conserving techniques may avoid the need for anticoagulation. Use of a valve-conserving procedure has been controversial as it is suggested that further deterioration of the aortic valve leaflets will require later valve replacement surgery. Recent case series have suggested that in expert hands, and in selected cases such as those where the aortic valve appears structurally normal (incompetence being due to annular dilatation), the longterm outcome is as good as the Bentall procedure, without the hazards of anticoagulation. ${ }^{43,44}$ There is certainly a case for considering this option for children, women of childbearing age and those in whom anticoagulation may be hazardous. As Marfan patients survive longer, re-operation for new aneurysms developing elsewhere in the arterial tree are becoming common - in one series, 70\% developed second aneurysms requiring surgery. ${ }^{39}$ Continuation of long-term medical prophylaxis after surgery is therefore strongly recommended ${ }^{42}$ along with follow-up imaging of the descending and abdominal aorta. ${ }^{41}$ Other cardiac valves may also be involved - mitral valve surgery is required in up to $10 \%$ of those requiring aortic root surgery. ${ }^{39}$

\section{Ocular system}

Ocular features of Marfan syndrome include bilateral ectopia lentis (40-56\%), myopia (28\%) and retinal detachment $(0.78 \%)^{5,45}$ Lens dislocation into the anterior chamber may occur. Subluxation usually develops in early childhood, but may first appear in the second decade. ${ }^{46}$ Myopia is associated with an increased length of the globe and an increased risk of retinal detachment. ${ }^{47}$ Early detection and correction of refractive errors prevents amblyopia - correction after the age of 12 years is unlikely to restore visual acuity. Anisotropia (unequal refraction between the two eyes) and the possible anterior chamber abnormalities are further important considerations for management. ${ }^{47}$ Ophthalmology assessment is important, and regular orthoptic review is recommended, particularly in childhood. Vitreolensectomy with laser prophylaxis to prevent retinal detachment can be effective in improving visual acuity in some patients. ${ }^{48}$

\section{Musculoskeletal system}

Skeletal abnormalities develop and may progress during childhood. Scoliosis affects around $60 \%$ of Marfan patients and may progress rapidly during growth spurts, leading to marked deformity, pain and restricted ventilatory deficit. ${ }^{49}$ In adults, back pain (associated with scoliosis) is three times more frequent than in the general population. ${ }^{49}$ Occasionally scoliosis may progress in adult life especially 
if the angle of curvature is $>40^{\circ}$. Back pain is said to be more common in patients with dural ectasia but the evidence for this is problematic. Dural ectasia is present in $69 \%$ of Marfan patients by CT scan, and $95 \%$ by MRI imaging. ${ }^{50,51}$ In a study of 32 patients, dural ectasia was present in $76 \%$ of those with back pain and $41 \%$ of those without. ${ }^{52}$ Treatment of dural ectasia to manage back pain remains speculative. ${ }^{50}$ Similarly, bone mineral density appears to be reduced at the spine and hip in Marfan syndrome, ${ }^{53,54}$ but no associated increase in fracture rate has been observed.

Joint hypermobility is common, affecting $85 \%$ of children under 18 , and $56 \%$ of adults with many patients suffering arthralgia, myalgia or ligamentous injury. ${ }^{55} \mathrm{~A}$ Marfan-related myopathy with abnormal muscle fibrillin was described in one family ${ }^{56}$ causing skeletal and respiratory muscle weakness. The significance of this for musculoskeletal symptoms in the wider Marfan patient group awaits further study.

\section{Respiratory system}

Pectus excavatum occurs in approximately two-thirds of patients with Marfan's syndrome, and when severe, can be associated with a restrictive ventilatory defect. ${ }^{57,58}$ It can cause difficulty with cardiac surgical procedures but correction is most often requested for cosmetic reasons. Patients with Marfan's syndrome are more likely to have delayed wound healing following repair of pectus excavatum. ${ }^{59,60}$ Surgical correction in children should be avoided, as recurrence is common in this age group. ${ }^{60}$

Spontaneous pneumothorax occurs in $4-11 \%$ of patients and may be associated with apical bullae. ${ }^{61,62}$ Recurrence is common, and there should be a low threshold for surgical intervention. Mechanical ventilation can exacerbate respiratory difficulties in Marfan neonates because of susceptibility to pneumothorax, bullae and emphysema.

Adult patients with Marfan syndrome have an increased tendency to upper airway collapse during sleep, causing obstructive sleep apnoea. This is associated with abnormalities of craniofacial structure. It may contribute to daytime somnolence, sometimes attributed to $\beta$-blocker therapy. $^{63}$

\section{Central nervous system}

Dural ectasia may reduce the effectiveness of epidural anaesthesia, ${ }^{64}$ and has been associated with intracranial hypotension-associated headache in a few case reports. ${ }^{65}$ Anterior sacral meningocele has been described rarely as a complication of Marfan syndrome, and may lead to diagnostic confusion when presenting as a pelvic or abdominal mass. ${ }^{66}$ Cerebral haemorrhage and other neurovascular disorders are uncommon in Marfan patients, ${ }^{67}$ but intracranial aneurysms may be more common in the Loeys-Dietz syndrome. ${ }^{13}$

\section{Pregnancy in Marfan syndrome}

The risk of aortic dissection in pregnancy is increased, probably due to inhibition of collagen and elastin deposition in the aorta by oestrogen, and the hyperdynamic hypervolaemic circulatory state of pregnancy. ${ }^{68}$ Conditions such as gestational hypertension and pre-eclampsia may be additional risk factors. ${ }^{69}$ Aortic dissection occurs in around $4.5 \%$ of pregnancies in women with Marfan syndrome ${ }^{69}$ and the risk is greater if the aortic root exceeds $4 \mathrm{~cm}$ at the start of pregnancy, or if it dilates rapidly. ${ }^{70}$ More frequent monitoring of aortic diameter in pregnancy is advisable. The rate of aortic dilatation is greater in women who have been pregnant with an aortic root diameter of more than $4 \mathrm{~cm}$, than in women who have remained childless, or women with children whose aortic root is less than $4 \mathrm{~cm} .^{71}$ The long-term consequences of this are uncertain, but extrapolation might suggest an increased risk of later aortic dissection/aortic root replacement. If the aortic root dilates to $5 \mathrm{~cm}$ during the pregnancy, consideration should be given to immediate aortic replacement, early delivery or termination of pregnancy. No increased risk of spontaneous pre-term labour, spontaneous miscarriage or postpartum haemorrhage has been observed.

As Marfan syndrome is autosomal dominant, there is a 1 in $2(50 \%)$ chance that the child of an affected person will inherit the disorder. Marfan patients seldom ask for prenatal diagnosis, although pre-implantation genetic diagnosis would be feasible in families with prior molecular work up in the genetic clinic. Ultrasound diagnosis is unreliable. Marfan patients should be offered genetic counselling before planning a family.

It is often difficult to diagnose Marfan syndrome in a newborn baby, but offspring of Marfan patients should be assessed early in life, with gene testing where possible, so that appropriate follow-up can be organised.

\section{Marfan syndrome and sports}

Although there have been no trials to investigate the effectiveness of sports limitation to avoid joint damage, common sense suggests that activities likely to stress the joints should be avoided. Heart rate, systolic blood pressure and cardiac output increase during both dynamic exercise (eg running) and static exercise (eg weight lifting). Peripheral vascular resistance and diastolic blood pressure tend to fall during dynamic exercise, but increase during static exercise. ${ }^{72}$ Marfan patients should therefore avoid high intensity static exercise, but can be encouraged to participate in lower intensity dynamic exercise. ${ }^{41,73}$ Contact sports are not advised to protect the aorta and the lens of the eye, and scuba diving should be avoided because of the increased risk of pneumothorax. 


\section{Conclusion}

The Ghent nosology remains the most effective way of diagnosing or excluding Marfan syndrome, provided its limitations with respect to children are not forgotten. It can help to identify families with aortic dissection who do not have Marfan syndrome, but it should not be used to assess risk in such families. Despite the morbidity and mortality associated with Marfan syndrome, appropriate medical and surgical management can improve and extend the lives of many patients, and advancing research holds the promise of further improvements in the future.

\section{Acknowledgements}

This article is based on work undertaken in conjunction with colleagues from many disciplines who formed the Scottish Marfan syndrome Guideline Development Group as part of a project funded by the Clinical Resources and Audit Group of the Scottish Executive Department of Health.

\section{References}

1 Gray JR, Bridges AB, West RR et al: Life expectancy in British Marfan syndrome populations. Clin Genet 1998; 54: 124-128.

2 Dietz HC, Cutting GR, Pyeritz RE et al: Marfan syndrome caused by a recurrent de novo missense mutation in the fibrillin gene. Nature 1991; 352: 337-339.

3 Dietz HC, Pyeritz RE: Mutations in the human gene for fibrillin-1 (FBN1) in the Marfan syndrome and related disorders. Hum Mol Genet 1995; 4: 1799-1809.

4 Loeys B, Nuytinck L, Delvaux I, De Bie S, De Paepe A: Genotype and phenotype analysis of 171 patients referred for molecular study of the fibrillin-1 gene FBN1 because of suspected Marfan syndrome. Arch Intern Med 2001; 161: 2447-2454.

5 Loeys B, De Backer J, Acker P et al: Comprehensive molecular screening of the FBN1 gene favors locus homogeneity of classical Marfan syndrome. Hum Mutat 2004; 24: 140-146.

6 Mizuguchi T, Collod-Beroud G, Akiyama T et al: Heterozygous TGFBR2 mutations in Marfan syndrome. Nat Genet 2004; 36: $855-860$.

7 Singh KK, Rommel K, Mishra A et al: TGFBR1 and TGFBR2 mutations in patients with features of Marfan syndrome and Loeys-Dietz syndrome. Hum Mutat 2006; 27: 770-777.

8 Sakai H, Visser R, Ikegawa S et al: Comprehensive genetic analysis of relevant four genes in 49 patients with Marfan syndrome or Marfan-related phenotypes. Am J Med Genet A 2006; 140: $1719-1725$.

9 Mizuguchi T, Matsumoto N: Recent progress in genetics of Marfan syndrome and Marfan-associated disorders. J Hum Genet 2007; 52: $1-12$.

10 Pannu H, Fadulu VT, Chang J et al: Mutations in transforming growth factor-beta receptor type II cause familial thoracic aortic aneurysms and dissections. Circulation 2005; 112: $513-520$

11 Law C, Bunyan D, Castle B et al: Clinical features in a family with an $\mathrm{R} 460 \mathrm{H}$ mutation in transforming growth factor beta receptor 2 gene. J Med Genet 2006; 43: 908-916.

12 Loeys BL, Chen J, Neptune ER et al: A syndrome of altered cardiovascular, craniofacial, neurocognitive and skeletal development caused by mutations in TGFBR1 or TGFBR2. Nat Genet 2005; 37: 275-281.

13 Loeys BL, Schwarze U, Holm T et al: Aneurysm syndromes caused by mutations in the TGF-beta receptor. $N$ Engl J Med 2006; 355: $788-798$.
14 De Paepe A, Devereux RB, Dietz HC, Hennekam RC, Pyeritz RE: Revised diagnostic criteria for the Marfan syndrome. Am J Med Genet 1996; 62: 417-426.

15 Campbell H, Bradshaw N, Davidson R et al: Evidence based medicine in practice: lessons from a Scottish clinical genetics project. J Med Genet 2000; 37: 684-691.

16 SIGN Guideline Development Handbook (SIGN50): Scottish Intercollegiate Guidelines Network, March 2004, http://www.sign. ac.uk/methodology/index.html.

17 Roman MJ, Rosen SE, Kramer-Fox R, Deverereux RB: Prognostic significance of the pattern of aortic root dilation in the Marfan syndrome. J Am Coll Cardiol 1993; 22: 1470-1476.

18 Yule SR, Hobson EE, Dean JCS, Gilbert FJ: Protrusio acetabuli in Marfan's syndrome. Clin Radiol 1999; 54: 95-97.

19 Shores J, Berger KR, Murphy EA, Pyeritz RE: Progression of aortic dilatation and the benefit of long-term beta-adrenergic blockade in Marfan's syndrome. N Engl J Med 1994; 330: 1335-1341.

20 Lipscomb KJ, Clayton-Smith J, Harris R: Evolving phenotype of Marfan's syndrome. Arch Dis Child 1997; 76: 41-46.

21 Joseph KN, Kane HA, Milner RS, Steg NL, Williamson MB, Bowen JR: Orthopedic aspects of the Marfan phenotype. Clin Orthop Relat Res 1992; 277: 251-261.

22 Gelb BD: Marfan's syndrome and related disorders - more tightly connected than we thought. New Engl J Med 2006; 355: 841-844.

23 Dietz HC, Loeys B, Carta L, Ramirez F: Recent progress towards a molecular understanding of Marfan syndrome. Am J Med Genet $C$ Semin Med Genet 2005; 139: 4-9.

24 Habashi JP, Judge DP, Holm TM et al: Losartan, an AT1 antagonist, prevents aortic aneurysm in a mouse model of Marfan syndrome. Science 2006; 312: 117-121.

25 Groenink M, Lohuis TAJ, Tijssen JG et al: Survival and complication free survival in Marfan's syndrome: implications of current guidelines. Heart 1999; 82: 499-504.

26 Legget ME, Unger TA, O'Sullivan CK et al: Aortic root complications in Marfan's syndrome: identification of a lower risk group. Heart 1996; 75: 389-395.

27 Meijboom LJ, Timmermans J, Zwinderman AH, Engelfriet PM, Mulder BJ: Aortic root growth in men and women with the Marfan's syndrome. Am J Cardiol 2005; 96: 1441-1444.

28 Rios AS, Silber EN, Bavishi N, Burton BK, Clark WA, Denes P: Effect of long-term beta-blockade on aortic root compliance in patients with Marfan syndrome. Am Heart J 1999; 137: 1057-1061.

29 Adams JN, Brooks M, Redpath TW et al: Aortic distensibility and stiffness index measured by magnetic resonance imaging in patients with Marfan's syndrome. Br Heart J 1995; 73: 265-269.

30 Salim MA, Alpert BS, Ward JC, Pyeritz RE: Effect of betaadrenergic blockade on aortic root rate of dilation in the Marfan syndrome. Am J Cardiol 1994; 74: 629-633.

31 Haouzi A, Berglund H, Pelikan PCD, Maurer G, Siegel RJ Heterogeneous aortic response to acute beta-adrenergic blockade in Marfan syndrome. Am Heart J 1997; 133: 60-63.

32 Groenink M, de Roos A, Mulder BJM, Spaan JAE, van der Wall EE: Changes in aortic distensibility and pulse wave velocity assessed with magnetic resonance imaging following beta-blocker therapy in the Marfan syndrome. Am J Cardiol 1998; 82: 203-208.

33 Rossi-Foulkes R, Roman MJ, Rosen SE et al: Phenotypic features and impact of beta blocker or calcium agonist therapy on aortic lumen size in the Marfan syndrome. Am J Cardiol 1999, 83: $1364-1368$

34 Nagashima H, Sakomura Y, Aoka Y et al: Angiotensin II type 2 receptor mediates muscle cell apoptosis in cystic medical degeneration associated with Marfan's syndrome. Circulation 2001; 104 (Suppl I): I-282-I-287.

35 Yetman AT, Bornemeier AT, McCrindle BW: Usefulness of enalapril versus propranolol or atenolol for prevention of aortic dilation in patients with the Marfan syndrome. Am J Cardiol 2005; 95: 1125-1127.

36 Wilson DG, Bellamy MF, Ramsey MW et al: Endothelial function in Marfan syndrome. Circulation 1999; 99: 909-915. 
37 Meijboom LJ, Nollen GJ, Mulder BJM: Prevention of cardiovascular complications in the Marfan syndrome. Vasc Dis Prev 2004; 1: 79-86.

38 Gott VL, Greene PS, Alejo DE et al: Replacement of the aortic root in patients with Marfan's syndrome. N Engl J Med 1999; 340: $1307-1313$.

39 Finkbohner R, Johnston D, Crawford S, Coselli J, Milewicz DM: Marfan syndrome. Long-term survival and complications after aortic aneurysm repair. Circulation 1995; 91: 728-733.

40 de Oliveira NC, David TE, Ivanov J et al: Results of surgery for aortic root aneurysm in patients with Marfan syndrome. J Thorac Cardiovasc Surg 2003; 125: 789-796.

41 Nataf P, Lansac E: Dilatation of the thoracic aorta: medical and surgical management. Heart 2006; 92: 1345-1352.

42 Treasure T: Elective replacement of the aortic root in Marfan's syndrome. Br Heart J 1993; 69: 101-103.

43 Bassano C, De Matteis GM, Nardi P et al: Mid-term follow-up of aortic root remodelling compared to Bentall operation. Eur J Cardio-Thorac Surg 2001; 19: 601-605.

44 Kallenbach K, Karck M, Pak D et al: Decade of aortic valve sparing reimplantation: are we pushing the limits too far? Circulation 2005; 112 (Suppl 9): I253-I259.

45 van den Berg JS, Limburg M, Hennekam RC: Is Marfan syndrome associated with symptomatic intracranial aneurysms? Stroke 1996; 27: 10-12.

46 Maumenee IH: The eye in the Marfan syndrome. Tr Am Ophth Soc 1981; 79: 684-733.

47 Pyeritz RE, McKusick VA: The Marfan syndrome: diagnosis and management. $N$ Engl J Med 1979; 300: 772-777.

48 Hubbard AD, Charteris DG, Cooling RJ: Vitreolensectomy in Marfan's syndrome. Eye 1998; 12: 412-416.

49 Pyeritz RE, Francke U: The second international symposium on the Marfan syndrome. Am J Med Genet 1993; 47: 127-135.

50 Fattori R, Nienaber CA, Descovich B et al: Importance of dural ectasia in phenotypic assessment of Marfan's syndrome. Lancet 1999; 354: 910-913.

51 Oosterhof T, Groenink M, Hulsmans FJ et al: Quantitative assessment of dural ectasia as a marker for Marfan syndrome. Radiology 2001; 220: 514-518.

52 Ahn NU, Sponseller PD, Ahn UM, Nallamshetty L, Kuszyk BS, Zinreich SJ: Dural ectasia is associated with back pain in Marfan syndrome. Spine 2000; 25: 1562-1568.

53 Le Parc JM, Molcard S, Tubach F: Bone mineral density in Marfan syndrome. Rheumatology (Oxford) 2001; 40: 358-359.

54 Giampietro PF, Peterson M, Schneider R et al: Assessment of bone mineral density in adults and children with Marfan syndrome. Osteoporos Int 2003; 14: 559-563.

55 Grahame R, Pyeritz RE: The Marfan syndrome: joint and skin manifestations are prevalent and correlated. Br J Rheumatol 1995; 34: 126-131.

56 Behan WM, Longman C, Petty RK et al: Muscle fibrillin deficiency in Marfan's syndrome myopathy. I Neurol Neurosurg Psychiatry 2003; 74: 633-638.
57 Scherer LR, Arn PH, Dressel DA, Pyeritz RM, Haller Jr JA: Surgical management of children and young adults with Marfan syndrome. J Pediatr Surg 1988; 23: 1169-1172.

58 Streeten EA, Murphy EA, Pyeritz RE: Pulmonary function in the Marfan syndrome. Chest 1987; 91: 408-412.

59 Golladay ES, Char F, Mollitt DL: Children with Marfan's syndrome and pectus excavatum. Southern Med J 1985; 78: $1319-1323$.

60 Arn PH, Scherer LR, Haller Jr JA, Pyeritz RE: Outcome of pectus excavatum in patients with Marfan syndrome and in the general population. J Pediatr 115; 1989: 957-958.

61 Hall JR, Pyeritz RE, Dudgeon DL, Haller JA: Pneumothorax in the Marfan syndrome: prevalence and therapy. Ann Thorac Surg 1984; 37: $500-504$

62 Wood JR, Bellamy D, Child AH, Citron KM: Pulmonary disease in patients with Marfan syndrome. Thorax 1984; 39: 780-784.

63 Cistulli PA, Gotsopoulos H, Sullivan CE: Relationship between Craniofacial abnormalities and sleep-disordered breathing in Marfan's syndrome. Chest 2001; 120: 1455-1460.

64 Lacassie HJ, Millar S, Leithe LG, Muir et al: Dural ectasia: a likely cause of inadequate spinal anaesthesia in two parturients with Marfan's syndrome. Br J Anaesth 2005; 94: 500-504.

65 Rosser T, Finkel J, Vezina G, Majd M: Postural headache in a child with Marfan syndrome: case report and review of the literature. J Child Neurol 2005; 20: 153-155.

66 Voyvodic F, Scroop R, Sanders RR: Anterior sacral meningocele as a pelvic complication of Marfan syndrome. Aust NZ J Obstet Gynaecol 1999; 39: 262-265.

67 Wityk RJ, Zanferrari C, Oppenheimer S: Neurovascular complications of Marfan syndrome: a Retrospective, Hospital-Based Study. Stroke 2002; 33: 680-684.

68 Immer FF, Bansi AG, Immer-Bansi AS et al: Aortic dissection in pregnancy: analysis of risk factors and outcome. Ann Thorac Surg 2003; 76: 309-314.

69 Chow SL: Acute aortic dissection in a patient with Marfan's syndrome complicated by gestational hypertension. Med J Aust 1993; 159: 760-762.

70 Lind J, Wallenburg HCS: The Marfan syndrome and pregnancy: a retrospective study in a Dutch population. Eur J Obstet Gynaecol Reprod Biol 2001; 98: 28-35

71 Meijboom LJ, Drenthen W, Pieper PG et al: On behalf of the ZAHARA investigators. Obstetric complications in Marfan syndrome. Int J Cardiol 2006; 110: 53-59.

72 Salim MA, Alpert BS: Sports and Marfan syndrome - awareness and early diagnosis can prevent sudden death. Phys Sportsmed 2001; 29: 80-93 (http://www.physsportsmed.com/issues/2001/ 05_01/salim.htm).

73 Maron BJ, Chaitman BR, Ackerman MJ et al: Recommendations for physical activity and recreational sports participation for young patients with genetic cardiovascular diseases. Circulation 2004; 109: 2807-2816. 